\title{
РАСПРОСТРАНЕННОСТЬ ХРОНИЧЕСКОГО БРОНХИТА У ПОДРОСТКОВ ПО ДАННЫМ ЭПИДЕМИОЛОГИЧЕСКИХ ИССЛЕДОВАНИЙ И ИХ КЛИНИЧЕСКАЯ ОЦЕНКА
}

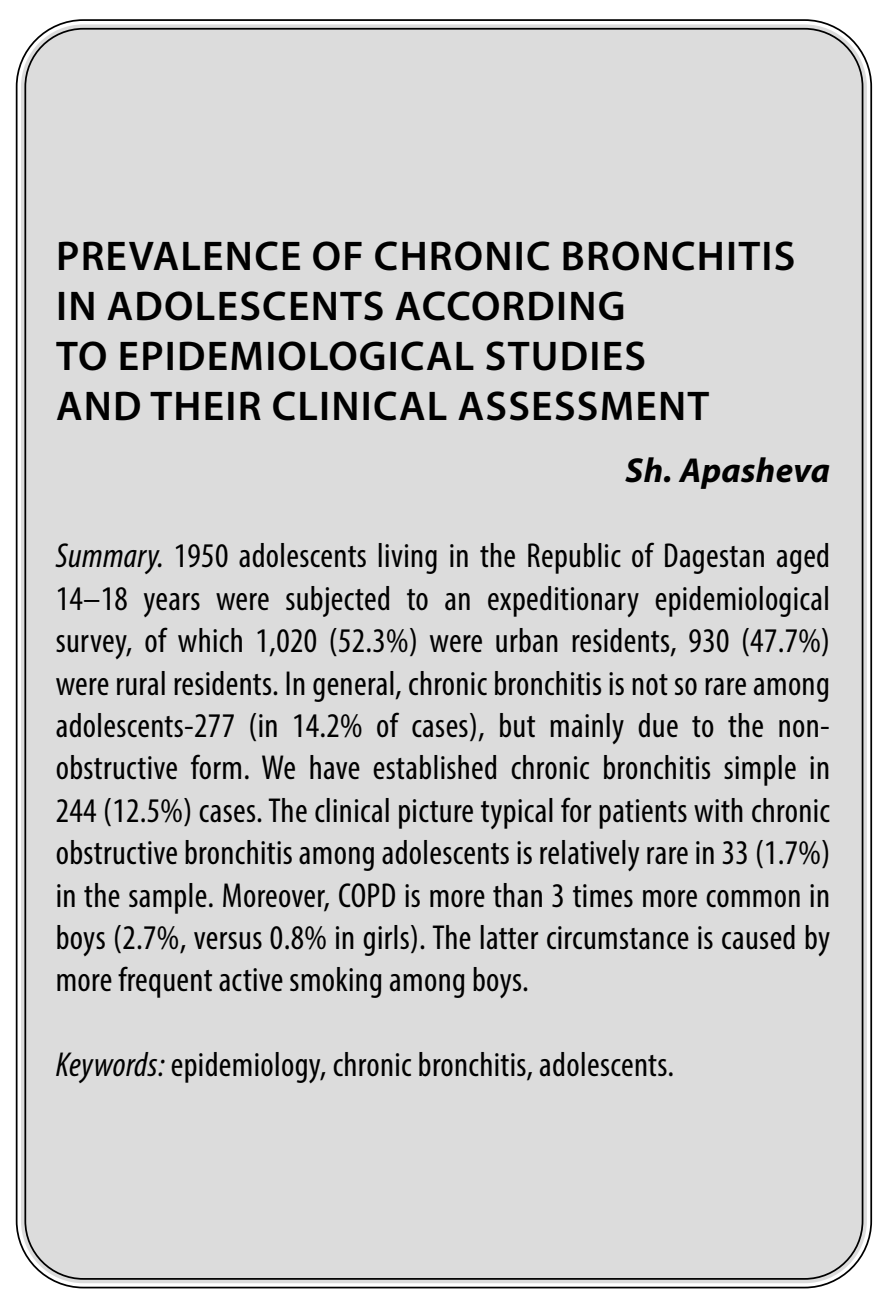

B последние годы в связи с неблагоприятными демографическими сдвигами усилился интерес к репродуктивному здоровью детей и подростков, поскольку именно с подростками связана надежда на улучшение качества здоровья ближайших поколений (3). В Республике Дагестан вовсе не изучены вопросы распространенности ХБ у подростков. Решению этих вопросов и было посвящено наше исследование.

Следует подчеркнуть, что ХБ у подростков не имеет ничего общего с клинической картиной подобной болезни у взрослых, которая именуется по современным понятиям как ХОБЛ. Скорее всего, у этой категории больных более оправданным является понятие ХБ простого (ХБП) и ХБ обструктивного (ХОБ).(2)

\author{
Апашева Шуанат Ахмеднабиевна \\ К.м.н., дочент, ФГБОУ ВО "Дагестанский \\ государственный медицинский университет" \\ Минздрава России \\ shuanadoctor@mail.ru
}

Аннотация. Экспедиционному эпидемиологическому обследованию подвергнуто 1950 подростков, проживающих в республике Дагестан в возрасте 14-18 лет, из которых городских жителей было 1020 (52,3\%), сельских жителей-930 (47,7\%). В целом среди подростков хронический бронхит выявляется не так редко-277 (в 14,2\% случаев), но в основном за счет необструктивной формы. Хронический бронхит простой нами установлен в 244(12,5\%) случаев. Клиническая картина, типичная для хронического обструктивного бронхита, среди подростков выявляется относительно редко в 33(1,7\%) в выборке. Причем более чем в 3 раза чаще ХОБ встречается у мальчиков (2,7\%, против 0,8\%-у девочек). Последнее обстоятельство вызвано с более частым активным курением среди мальчиков.

Ключевые слова: хронический бронхит, эпидемиология, подростки.

\section{Цель исслеАования}

Изучить распространенность хронического бронхита у подростков в зависимости от факторов экосистемы и климатических зон в республике Дагестан.

\section{Материал и методы исслеАования}

Анкетному опросу подвергнуто 1950 подростков, проживающих в различных климатических зонах республики Дагестан. На первом этапе тщательному анализу подвергались респираторные симптомы, анамнез как активного, так и пассивного курения, проводилась аускультация, изучался показатель ПФМ. 
Таблица 1. Частота респираторных симптомов у обследованных в различных климатических зонах (в \% от общего количества в группах).

\begin{tabular}{|l|l|l|l|l|l|} 
Показатель & $\begin{array}{l}\text { Село -горы } \\
(\mathbf{n = 6 2 9 )}\end{array}$ & $\begin{array}{l}\text { Село-равнина } \\
(\mathbf{n = 3 0 1 )}\end{array}$ & $\begin{array}{l}\text { Город } \\
(\mathbf{n = 1 0 2 0 )}\end{array}$ & $\begin{array}{l}\text { Всего } \\
(\mathbf{n}=\mathbf{1 9 5 0 )}\end{array}$ & $\mathbf{P}$ \\
\hline Кашель & 12,5 & $21,5^{* *}$ & 11,2 & 15,06 & $<0,05$ \\
\hline Мокрота & 31,5 & $11,8^{* *}$ & 30,4 & 21,2 & $<0,05$ \\
\hline Одышка & 14,4 & $13,3^{* *}$ & $28,6^{*}$ & 18,8 & $>0,05$ \\
\hline
\end{tabular}

* -разница достоверна между село (горы) и городом

** - разница достоверна между селом (равнина) -и городом

p - разница достоверна между селом (горы) и равниной

Таблица 2. Число активных и пассивных курильщиков среди обследованного контингента подростков в зависимости от пола.

\begin{tabular}{|l|l|l|l|}
\hline Группа исследованных & $\begin{array}{l}\text { Мальчики } \\
(\mathbf{n = 9 2 5 )}\end{array}$ & $\begin{array}{l}\text { Девочки } \\
(\mathbf{n}=1025)\end{array}$ & Bсего $(\mathbf{n}=1950)$ \\
\hline $\begin{array}{l}\text { Активные } \\
\text { курильщики }\end{array}$ & $176(19,0 \%)$ & - & $176(9,0 \%)$ \\
\hline $\begin{array}{l}\text { Пассивные } \\
\text { курильщики }\end{array}$ & $430(46,5 \%)$ & $602(58,7 \%)$ & $1032(52,9 \%)$ \\
\hline Итого & $606(65,5 \%)$ & $602(58,7 \%)$ & $1208(61,9 \%)$ \\
\hline
\end{tabular}

На втором этапе обследования, лицам подозрительным на наличие ХБ записывались 36 параметров ФВД, а при наличии исходных признаков обструкции и ингаляционная дилатационная проба с беротеком. Кроме того, определялся уровень сенсибилизации организма с помощью подсчета количества эозинофилов в крови и уровня сывороточного иммуноглобулина $\mathrm{E}$.

\section{Результаты исслеАования}

Основными жалобами, подвергнутыми анализу, были кашель, выделение мокроты, одышка при физической нагрузке.

В следующей таблице 1 представлены данные о частоте респираторных симптомов у обследованных подростков в различных климатических зонах.

Кашель статистически значимо чаще наблюдается у подростков, проживающих в сельской приморской зоне (21,5\%), что, по видимому, вызвано наличием в данном поселке нескольких кирпичных заводов. Разница между остальными группами оказалась статистически значимой ( $p=0,046$ и 0,042).

В целом в группе обследованных выделение мокроты отмечено в 21,2\% случаев и существенно чаще среди городских подростков (30,4\%), чем остальных двух группах обследованных сельских жителей $(11,8 \%$ и $21,5 \%$ соответственно)
Из литературных источников известно, что одним из ведущих экзогенных факторов, способствующих развитию ХБ у детей и ХОБЛ у взрослых, является курение, как активное, так и пассивное. Среди обследованных подростков число курильщиков оказалось достаточно много, что представлено в таблице 2. Положительный ответ на наличие факта активного курения дали 176 $(19,1 \%)$ респондентов мужского пола. При этом анамнез активного курения у мальчиков имел продолжительность от нескольких месяцев до 5 лет.

Из них 128 подростков с детства являлись и пассивными курильщиками с продолжительностью контакта с табачным дымом в пределах 10-15 лет. Девочки положительного ответа на факт активного курения не дали ни в одном случае. Но достаточно высокий процент пассивного курения наблюдался и среди девочек (58,2\%). Мальчиков пассивных курильщиков, в выборке оказалось несколько меньше (46,5\%). Следует подчеркнуть достаточно высокий процент активного и пассивного курения среди мальчиков (65,5\%).

На основании наших эпидемиологических данных и тщательной оценки анамнеза, клинико-инструментально-лабораторных показателей, удалось установить, что характерные для ХБ клинические симптомы (кашель, мокрота) наблюдались у 277 подростка, из которых обструкция бронхов (одышка в покое, снижение $\left.\mathrm{OФB}_{l}\right)$, выявлены только у 33 человек (1,7\% от общего числа обследованных). Эти данные изложены в табли- 
Таблица 3. Распространенность ХБ среди подростков в зависимости от пола и тяжести течения (абс. числ. и в\%.)

\begin{tabular}{|l|l|l|l|}
\hline \multirow{2}{*}{ Группы исследованных } & ХБП & ХОБ & Всего \\
\cline { 2 - 4 } & $175(18,9 \%)$ & $25(2,7 \%)$ & $200(21,6 \%)$ \\
\hline $\begin{array}{l}\text { Мальчики } \\
(n=925)\end{array}$ & $69(6,7 \%)$ & $8(0,8 \%)$ & $77(7,5 \%)$ \\
\hline $\begin{array}{l}\text { Девочки } \\
(n=1025)\end{array}$ & $244(12,5 \%)$ & $33(1,7 \%)$ & $277(14,2 \%)$ \\
\hline
\end{tabular}

Таблица 4. Частота перенесенной острой респираторной патологии у больных ХБ в различных стадиях течения (абс. число и\%)

\begin{tabular}{|l|l|l|l|}
\hline Диагноз & ХБП $\mathbf{n = 2 4 4}$ & ХОБ $\mathbf{n = 3 3}$ & Bсего $\mathbf{n = 2 7 7}$ \\
\hline ОП & $23(9,4)$ & $9(27,3)$ & $32(11,6)$ \\
\hline Острый бронхит & $32(13,1)$ & $10(30,3)$ & $42(15,2)$ \\
\hline Итого & $55(22,5)$ & $19(57,6)$ & $74(26,7)$ \\
\hline
\end{tabular}

Таблица 5. Показатели ФВД у здоровых и больных подростков, страдающих ХБ в процентах к должной $(\mathrm{M}+\mathrm{m})$

\begin{tabular}{|c|c|c|c|c|c|c|}
\hline Показатель & $\begin{array}{l}\text { Здоровые } \\
n=20\end{array}$ & $\begin{array}{l}\text { Больные } \\
\text { ХБ } \\
n=42\end{array}$ & $\begin{array}{l}\text { ХБП } \\
\mathrm{N}=19\end{array}$ & $\begin{array}{l}\text { ХОБ } \\
n=23\end{array}$ & $\mathbf{P}$ & $\mathbf{P}_{1}$ \\
\hline ЖЕЛ & $98,5+2,6$ & $88,6+3,1$ & $94,7+3,9$ & $82,5+3,6$ & $<0,05$ & $<0,05$ \\
\hline ФЖЕЛ & $107,0+2,5$ & $92,6+3,1$ & $96,9+3,8$ & $88,6+3,7$ & $<0,05$ & $<0,05$ \\
\hline $\mathrm{O}_{1}$ & $112,0+2,9$ & $88,9+3,2$ & $99,6+3,9$ & $78,2+3,9$ & $<0,01$ & $<0,05$ \\
\hline ОФВ ${ }_{l} /$ ФЖЕЛ & $105,0+2,6$ & $97,9+2,4$ & $102,8+3,9$ & $91,3+2,6$ & $<0,05$ & $<0,05$ \\
\hline MOC25 & $110,2+4,6$ & $77,9+2,7$ & $88,1+3,9$ & $67,7+3,9$ & $<0,001$ & $<0,05$ \\
\hline MOC50 & $107,0+6,6$ & $79,6+3,3$ & $93,4+3,7$ & $65,9+4,5$ & $<0,001$ & $<0,05$ \\
\hline MOC75 & $115,7+9,8$ & $79,5+3,7$ & $94,3+5,0$ & $64,7+5,4$ & $<0,001$ & $<0,05$ \\
\hline ПФМ & $98,4+3,4$ & $89,8+3,4$ & $98,8+5,4$ & $80,8+4,4$ & $<0,05$ & $<0,05$ \\
\hline $\mathrm{SpO}_{2} \mathrm{~B} \%$ & $96,0+0,4$ & $94,2+0,5$ & $95,3+0,8$ & $93,1+0,67$ & $<0,05$ & $>0,05$ \\
\hline $\begin{array}{l}\text { Средний } \\
\text { Возраст }\end{array}$ & $15,6+0,2$ & $15,8+0,2$ & $16,2+0,3$ & $15,4+0,38$ & & \\
\hline
\end{tabular}

Р - разница между здоровыми и больными ХБ;

P1- разница между больными ХБП и ХОБ значима

це 3. Основная масса больных - 244 из 277 (88,0\%) человек имели ХБ простой и периодически предъявляли жалобы на кашель более 2 месяцев в году, или выделение мокроты, или же и того и другого. Таких лиц в выборке составило $12,5 \%$ случаев.

Мальчики ХБ простой имели 175 человека из 925 обследованных (18,9\%), тогда как у девочек он обнаружен только у 69 из 1025 обследованных (6,7\%). Разница по полу статистически высоко значима $(p<0,001)$. Из 33 больных ХОБ 6 человек страдали бронхоэктатической болезнью, трое из которых были оперированы по поводу бронхоэктазов.
Одной из причин развития хронической легочной патологии является перенесенные в прошлом, в раннем детстве, острые респираторные болезни. В следующей таблице 4 представлены данные о перенесенных острой пневмонии и бронхита у больных ХБ. Как видно из представленных данных, 32 из 277 больных ХБ $(11,6 \%)$ имели в анамнезе перенесенную ОП и 42 $(15,2 \%)$ - острый бронхит. Чем тяжелее стадия ХБ, тем чаще наблюдались в анамнезе перенесенные острые респираторные заболевания.

У больных ХБ простым, ОП наблюдалась в 9,4\%, тогда как у больных ХОБ в 3 раза чаще (27,3\%). Такая же 


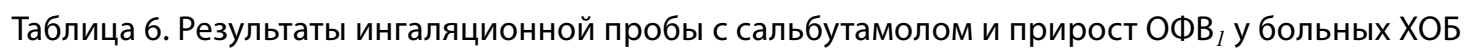
подростков

\begin{tabular}{|c|c|c|c|c|}
\hline \multirow[t]{2}{*}{$\begin{array}{l}\text { Степень } \\
\text { обструкции }\end{array}$} & \multicolumn{3}{|l|}{$\begin{array}{l}\text { Результаты } \\
\text { пробы }\end{array}$} & \multirow[t]{2}{*}{$\begin{array}{l}\text { Процент } \\
\text { прироста } \\
\text { ОФВ }_{1} \\
\end{array}$} \\
\hline & Положительная & сомнительная & Отрицательная & \\
\hline Легкая n=4 & - & - & 4 & $4,0+1,9$ \\
\hline Умеренная $\mathrm{n}=8$ & 1 & 1 & 6 & $6,0+1,8$ \\
\hline Значительная n=6 & - & 1 & 5 & $7,1+1,7$ \\
\hline Всего $n=18$ & $1(5,5)$ & $2(11,1)$ & $15(83,4)$ & $5,9+1,0$ \\
\hline
\end{tabular}

Таблица 7. Содержание общего IgE в крови, абсолютного количества эозинофилов в крови у здоровых подростков и больных ХОБ.

\begin{tabular}{|l|l|l|l|}
\hline Показатель & Здоровые =16 & Больные ХОБ =16 & $\mathbf{P}$ \\
\hline Уровень IgЕ в крови в МЕ/мл & $52,2+4,2$ & $59,7+12,6$ & $>0,05$ \\
\hline Абс. кол. Эозинофилов в х10\%/л & $0,180+0,03$ & $0,206+0,05$ & $>0,05$ \\
\hline Процент эозинофилов в крови & $2,2+0,3$ & $2,8+0,3$ & $>0,05$ \\
\hline
\end{tabular}

ситуация наблюдалась и с перенесенным в прошлом острым бронхитом. Острая респираторная инфекция в прошлом обнаружена у больных ХБП в 22,5\% случаев, а у больных ХОБ - более чем в 2,5 раза чаще $(57,6 \%$ случаев).

Сравнительный анализ показателей ФВД у здоровых и больных ХБ в зависимости от тяжести представлены в таблице 5.6. Как видно из данной таблицы в целом в группе больных ХБ (42 человека) все показатели ФВД, характеризующие бронхиальную проходимость, оказались ниже предельно допустимой нормы. Ниже принятых нормативов оказались все три показателя ФВД $\left(\mathrm{MOC}_{25,50,75}\right)$, оценивающие проходимость бронхов на различных уровнях (крупные - 77,9\%, средние - 79,6\%, мелкие - 79,5\%). Вместе с этим, как видно из таблицы 5.6 по сравнению со здоровыми подростками у больных ХБ все показатели ФВД оказались статистически значимо ниже ( $<<0,01)$. ЖЕЛ у здоровых составляла $98,5+2,6 \%$, у больных ХБ -88,6+3,1\%., а у больных ХОБ $-82,5+3,6 \%$.

У больных ХБП проходимость бронхов была нарушена всего в одном случае из 19 (5,3\%), тогда как у больных ХОБ, подобные изменения выявлены у 18 из 22 исследованных (81,81\%), в том числе, у 4 больных легкие, у 8 - умеренные и у 6 значительные.

Подобная симптоматика может быть и у больных БА, с которой приходиться проводить дифференциальную диагностику. Основным показателем, отличающим ХБ от БА по данным литературных источников является прирост ОФВ ${ }_{1}$ на фоне дилятационной пробы с сальбутамолом, который у наших больных ХОБ не превысил
$12 \% .(36,81,82)$, тогда как при БА он составляет более чем $20 \%$.

Результаты бронходилатационной пробы у больных ХОБ подростков с исходной обструкцией представлены в таблице 6.(5)

Ингаляционная дилатационная проба, проведенная 18 больным ХОБ с исходной обструкцией бронхов дали положительные результаты только у одного пациента (5,5\%), у которого в анамнезе присутствовала

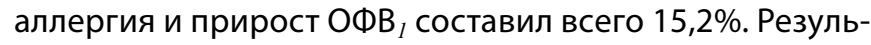
таты пробы были сомнительными в 2 случаях (прирост в пределах 10-14\%) и отрицательными в 83,4\% случаев. Средний прирост ОФВ ${ }_{1}$ после ингаляции сальбутамола в группе составил всего 5,9+1,0\%.

В целом в группе обследованных и у больных с тяжелым течение ХОБ и сатурация снижалась статистически значимо $(93,1+0,67 \%)$ по сравнению со здоровыми $(96,0+0,4 \%)$ подростками $(p<0,05)$.

В целях проведения дифференциальной диагностики с БА нами, кроме того, больным определялась концентрация общего IgЕ в сыворотке крови и абсолютное количество эозинофилов в крови и их процентное их содержание.

Данные исследования эозинофилов в крови и содержание общего lgЕ в представлены в таблице 7.

Только у 2 из 16 (12,5\%) больных ХОБ содержание общего IgЕ оказалось выше предельно допусти- 
мой концентрации (120 ME/мл) и колебалось в целом у больных в пределах 16-142 ME/мл (среднее содержание 59,7+12,6 MЕ/мл) и по сравнению со здоровыми подростками статистического отличия не имела. У двух больных ХОБ с высоким содержанием IgE обнаружена сопутствующая аллергия. Абсолютное количество эозинофилов в крови у больных ХОБ так же находилось в пределах нормальных цифр (0,206+0,05 X 10\% при 0,180+0,03; p>0,05) указывая на отсутствие аллергической сенсибилизации у этой группы больных.

Резюмируя представленные данные, следует подчеркнуть, что среди подростков ХБ выявляется не так редко (в 14,2\% случаев), но в основном за счет не обструктивной формы. ХБП нами установлен в 12,5\% случаев. Клиническая картина, типичная для больных ХОБ, с одышкой при физической нагрузке, обструктивными изменениями ФВД среди подростков выявляется относительно редко, у 33 человек из 277 больных ХБ, выявленных из 1950 обследованных (1,7\% в выборке). Причем более чем в 3 раза чаще ХОБ встречается у мальчиков $(2,7 \%$, против $0,8 \%$-у девочек). Последнее обстоятельство вызвано с более частым активным курением среди мальчиков. Показатели ФВД у больных ХБ снижены по сравнению со здоровыми подростками и у части из них они носят легкий и умеренный характер и у отдельных лиц имеет обратимый характер, что важно при планировании лечения и мер профилактики. Стратегически важным моментом является то, что в этой возрастной группе чаще наблюдается обратимая стадия болезни, ХБП (в 12,5\% случаев в выборке), что так же важно в целях профилактики ХОБЛ у взрослых. Основными этиологическими факторами служат пассивное или активное курение и перенесенные в прошлом острые респираторные заболевания. Распространенность ХБ у подростков мало изучена и не оценена его роль в возникновении ХОБЛ у взрослых. У взрослых ХОБЛ имеет, особенно во П-1У стадиях, ярко очерченную клиническую картину с только частично обратимой обструкцией бронхов $(43,44)$. У подростков эта болезнь чаще встречается в форме ХБ простого (необструктивного). Нет дыхательной недостаточности, цианоза, редко наблюдается легочное сердце. Но, по нашему глубокому убеждению, основы ХОБЛ у взрослых закладываются в подростковом и детским возрасте, когда они становятся активными или пассивными курильщиками.(1,9).

Наши исследования показали, что типичная картина ХОБ у подростков наблюдается в выборке только в 1,7\% случаев, причем чаще у лиц, страдающих врожденными брохоэктазами (6 случаев), у больных после сегментоэктомии по поводу бронхоэктазов (3 случая). При этом одно сильно настораживает то, что более $65,5 \%$ мальчиков являются активными и пассивными курильщиками, а 58,2\% девочек - пассивными курильщицами. Практически основная масса больных ХБ являлись «курильщиками» или же в детстве перенесли острую пневмонию, другую респираторную инфекцию. Особенностью течения ХБ у подростков является то, что у них нет выраженных не обратимых обструктивных нарушений. $(6,7,8)$. Завершить свою мысль в этом плане хочется пожеланием коллегам особое внимание уделить при обследовании больных подростков с легочной патологией анамнезу курения и с учетом этого строить превентивные меры.

\section{Выво $\triangle$}

1. Обязательным условием постановки диагноза хронический бронхит у подростков в сомнительных случаях является проведение функционально-фармакологических проб с бронходилататорами и бронхоконстрикторами.

2. Хронический обструктивный бронхит у подростков диагностируется всего в 1,7\% случаев, тогда как хронический бронхит простой встречается в 12,5\% случаев, что может служить основой развития в последующем хронической обструктивной болезни легких у взрослых.

3. Активное и пассивное курение является не только основной причиной развития хронического бронхита у подростков, но и одной из причин развития ХОБЛ у взрослого населения.

\section{ЛИТЕРАТУРА}

1. Алексеев С.В. Медико-социальная оценка здоровья современных подростков. Проблемы и пути их решения //Материалы 1У международного конгресса «Эколого-социальные вопросы защиты и охраны здоровья молодого поколения на пути в XX1 век».— СПб.-1998.-С.16-19.

2. Глобальная инициатива по ХОБЛ. Глобальная стратегия диагностики, лечения и профилактики хронической обструктивной болезни легких. Пересмотр 2003 г. Национальные институты здоровья США. Национальный институт сердца, легких и крови. //Атмосфера. - 2003. -96с.

3. Иванова Р.И. Распространенность неспецифических заболеваний легких у подростков в РС (Я). //Сб. Резюме. 12 Нац. Конгр. по бол. органов дыхания. - М., 2002,-С.399.

4. Ильясова Л.И., Загидуллин Ш.З., Эпидемиологические аспекты бронхолегочных заболеваний по данным обращаемости за скорой медицинской помощью. 4 Национальный конгресс по болезням органов дыхания. Москва. 15-19 марта 1994. //Сборник-резюме. -№ 1213. 
5. Калманова Е.Н. Ингаляционные провокационные тесты в пульмонологической практике.//Атмосфера. Пульмонология и аллергология. № 3(14), 2004, -С. 34-39.

6. Карелин А.О., Богданова А.В., Глушкова А.В. К вопросу о влиянии некоторых социальных факторов на формирование бронхолегочных заболеваний у детей крупного промышленного города. //Сборн. тезисов Междунар. Конгресс по туберк. и бол. орг. дыхания и 14 Нац конгр.по бол. орг. дых. Москва .-2004,C.439.

7. Таточенко В.К., Болезни органов дыхания (практическое руководство), М.: Педиатръ, 2012

8. Игнатова, Г.Л. Прогнозирование развития хронического бронхита и бронхиальной астмы у лиц молодого возраста: методические рекомендации / Г.Л. Игнатова, И.А. Захарова. - Челябинск: Изд-во государственного медицинского университета, 2016-8 с.

9. Захарова, И.А. Влияние курения на вентиляционную функцию легких в молодом возрасте / И.А. Захарова // Клиническая медицина. 2015 - № 3 C. $45-48$

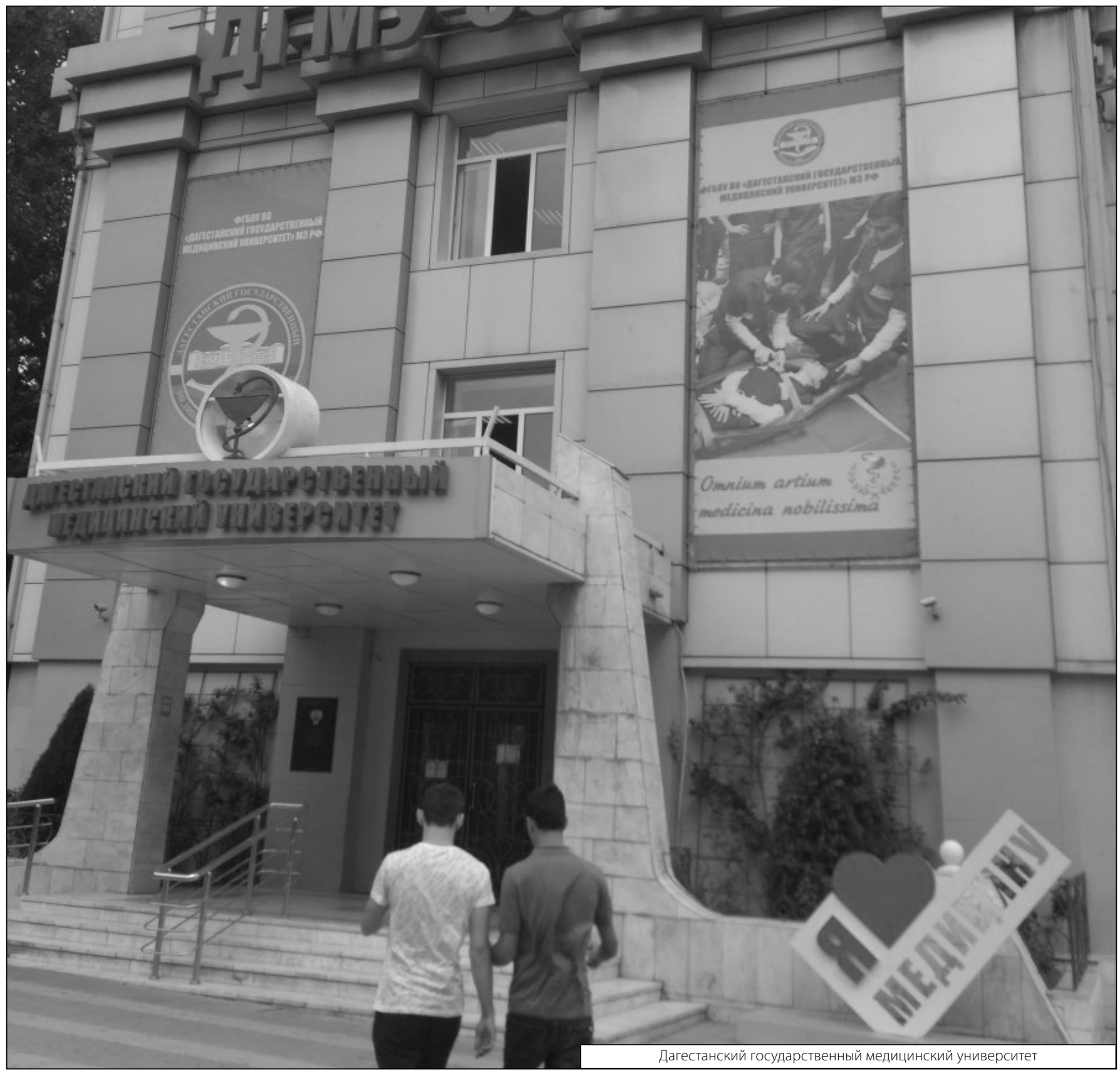

